\title{
The Optimization on FACTS Devices for Network Security
}

\author{
Yang Huaqing \\ College of Computer \\ Liaocheng University \\ Liaocheng, China \\ yanghuaqing563453@163.com
}

\author{
Yang Wenwen \\ School of Foreign Language Education \\ Liaocheng University \\ Liaocheng, China \\ yanghuaqing563453@163.com
}

\begin{abstract}
One of the most important indices which are used in FACTS devices placement are indices related to network security and its vulnerability. On this basis, objective function consisting of vulnerability indices of generators, lines and bus bars presented and placement is done simultaneously and nonsimultaneously. For case studies, placement of a UPFC, a TCSC and a SVC in IEEE 30 bus test system are performed simultaneously and non-simultaneously. The results have shown simultaneous placement of these devices improve vulnerability indices more than non-simultaneous placement.
\end{abstract}

\section{Keywords-FACTS devices, TCSC, Network Security}

\section{INTRODUCTION}

FACTS devices can reduce losses, improve voltage profiles, control transmission power flow and control power demanded from the power plants. Also, due to the expansion of power systems, network security has been more important and it is necessary to pay much more attentions on application of FACTS devices for network security indices. One of the major issues in the FACTS devices placement is optimizing a specified objective function by considering its corresponding constraints. For FACTS devices placement, in references [1 and 2] the objective function includes losses and transmitted power through transmission lines and in references [3 and 4], the placement of FACTS devices based on transmitted power sensitivity. In [5 and 6], voltage profile and transmitted power, and in [7] the optimal load flow are used for FACTS devices placement. In references [8 and 9], FACTS devices placement has been done based on the electricity market. Mentioned placement is done in [10] based on reactive power control and in [11] is done for network balancing. In references [12, 13, 14 and 15], the dynamic performance of network and in references [16 and 17], network security margin are considered as the objective function.

In this paper, since the network security margin is more important than any other system indices, network security margin and system vulnerabilities indices are considered as the objective function in placement of FACTS devices. Considered indices are the generators, lines and bus bars vulnerability indices.

\section{MODELING FACTS DEVICES}

The most widely used FACTS devices are: SVC, TCSC and UPFC. Models so far presented for this type of FACTS devices are in two dynamic and static models which further their static models will be examined.

\section{A. TCSC Model}

TCSC is a capacitor along with a parallel TCR is placed in series with a transmission line. Accordingly, from the viewpoint of power system, TCSC is variable impedance in series with transmission line, and according to Eq (1) leads to changes in line impedance. Also, in power flow problem, TCSC can only lead to change network impedance matrix. Fig. 1 shows the TCSC model based on the above explanation.

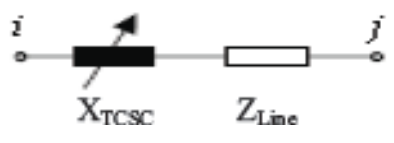

Figure 1. TCSC Model

$$
X_{\text {new }, L}=X_{\text {old }, L}+X_{\text {TCSC }}
$$

Where:

$X_{\text {old }, L}:$ Transmission line reactance before TCSC installation

$X_{\text {TCSC }}:$ Injected reactance by TCSC

$X_{\text {new }, L}$ : Transmission line reactance after TCSC installations.

\section{B. SVC Model}

SVC has several models that the most used model is Fixed Capacitor Thyristor Controlled Regulator (FCTCR). In fact, according to the Fig. $2 \mathrm{SVC}$ is a capacitor in parallel with a TCR which is connected in parallel with the network and can be used as compensating reactive power, hence it can be modeled as a variable reactive power source.

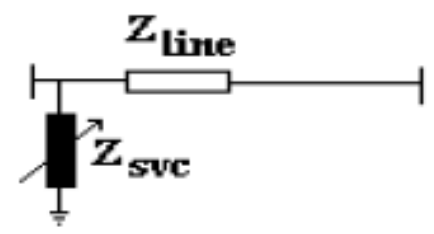

Figure 2. SVC Model

\section{UPFC Model}

As shown in Fig. 3-a, UPFC is combined of a series voltage source and a parallel current source. In this Figure, $V_{s e} \angle \varphi_{s e}$ is a series voltage source and $I_{s h q}$ is a parallel current source. From the viewpoint of power system, parallel 
devices can be modeled as the active and reactive power compensating. So, if the parallel part of UPFC decomposed into two sources of compensating reactive power and active power, reactive power compensating models will be similar to SVC and STATCOM and compensating active power will be equal to the series branch active power. For modeling series branch, according to Fig. 3-b, series voltage source with the line impedance will be transformed to the Norton's equivalent. Thus, according to Fig. 3-a, series branch can be considered as the active and reactive power compensating in two adjacent buses of transmission line. Series active and reactive power injection to bus $i$ and $j$ can be calculated using Eqs. (2)-(7).

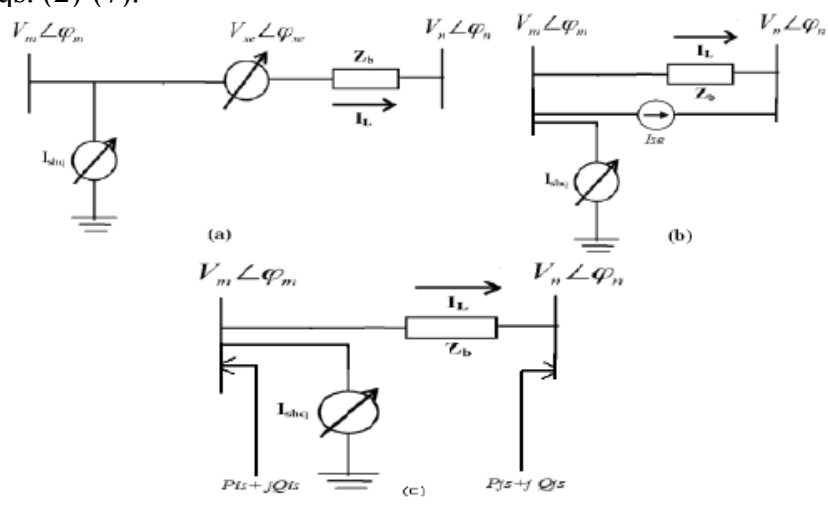

Figure 3. UPFC Model

$$
\begin{aligned}
& P_{i s e}=P_{s h} \\
& I_{s e}=\frac{V_{s e}}{Z_{l}} \\
& P_{i s e}=\operatorname{Re}\left\{V_{i} \times I_{s e}^{*}\right\}=-\operatorname{Re}\left\{V_{i} \times\left(\frac{V_{s e}}{Z_{l}}\right)^{*}\right\} \\
& Q_{i s e}=\operatorname{Imag}\left\{V_{i} \times I_{s e}^{*}\right\}=-\operatorname{Imag}\left\{V_{i} \times\left(\frac{V_{s e}}{Z_{l}}\right)^{*}\right\} \\
& P_{j s e}=\operatorname{Re}\left\{V_{j} \times I_{s e}^{*}\right\}=\operatorname{Re}\left\{V_{j} \times\left(\frac{V_{s e}}{Z_{l}}\right)^{*}\right\} \\
& Q_{j s e}=\operatorname{Imag}\left\{V_{j} \times I_{s e}^{*}\right\}=\operatorname{Imag}\left\{V_{j} \times\left(\frac{V_{s e}}{Z_{l}}\right)^{*}\right\}
\end{aligned}
$$

In which:

$P_{s h}:$ Active power injected by the parallel branch

$P_{i s e}$ : Active power injected into the ith bus by FACTS devices

$I_{s e}:$ Injected current by the series branch

$V_{s e}$ : Voltage injected by the series branch
$Z_{l}$ : Line impedance

$V_{i}$ : ith bus voltage

$Q_{\text {ise }}$ : Reactive power injected into ith bus by FACTS devices

$P_{\text {jse }}$ : Active power injected into jth bus by FACTS devices

$V_{j}$ : jth bus voltage

$Q_{j s e}:$ Reactive power injected into jth bus by FACTS devices

Similarly, parallel branch of UPFC can be regarded as a parallel reactive power source connected to the ith bus.

\section{OBJECTIVE FUNCTION}

In this paper, in order to consider the three indices of security margin, an objective function equation according to Eq (8) is considered.

$$
V I_{\text {sys }}=V I_{\text {bus }}+V I_{\text {line }}+V I_{\text {gen }}
$$

In which:

$V I_{\text {sys }}:$ System vulnerability index

$V I_{\text {bus }}$ : Bus bars' vulnerability index

$V I_{\text {line }}$ : Lines' vulnerability index

$V I_{\text {gen }}$ : Generators' vulnerability index.

Further, modeling abovementioned indices will be explained.

\section{MODELING SYSTEM VULNERABILITY INDICES}

System vulnerability indices can be extracted from the security margin indices. Modeling system security margin indices can be done for different purposes. In this paper, for FACTS devices placement, network security indices are regarded in three parts; lines, bus bars and generators security margins.

\section{A. Lines Security Margin Index}

The vulnerability and security margins of a transmission line in power systems can be depended on the line transmitted power and the phase displacement of the adjacent buses. Therefore, for modeling it, some indices can be presented as follows:

$$
\begin{aligned}
& V I_{L S}=\sqrt{\sum_{i=1}^{N L}\left(\frac{S_{i}}{S_{i, \max }}\right)^{2}} \\
& V I_{L \delta}=\sqrt{\sum_{i=1}^{N L}\left(\frac{\Delta \delta_{i}}{\Delta \delta_{i, \max }}\right)^{2}}
\end{aligned}
$$

Where:

$V I_{L S}$ : Line vulnerability index due to the transmitted power through it 
$V I_{L \delta}$ : Line vulnerability index due to the phase displacement of the adjacent buses

$S_{i}$ : ith bus power

$\Delta \delta_{i}$ : Phase displacement between adjacent buses connected via ith line

$S_{i, \max }$ : Capacity of transmitted power through ith line

$\Delta \delta_{i, \max }$ : The maximum phase displacement between adjacent power lines connected to the ith line

NL: Number of system lines

Therefore, the line vulnerability indices are obtained, totally, by the lines transmitted power vulnerability and the phase displacement between adjacent busses as Eq. (11).

$$
V I_{L}=W_{L} \bullet V I_{L S}+W_{L \delta} \bullet V I_{L \delta}
$$

In which, $\mathrm{W}_{\mathrm{L} \delta}, \mathrm{W}_{\mathrm{LS}}$ are weighting coefficients of VI $\mathrm{L} \delta, \mathrm{VI}_{\mathrm{LS}}$, respectively, and their values can be determined based on any of the indices. Of course, since in this paper minimizing the Eq. (8) is our object, therefore the vulnerability index is used in FACTS devices placement. While if the goal was maximizing the objective function, system security margin indices could be utilized.

\section{B. Bus bars Security Margin Indices}

In any power networks, vulnerability and security margin of any bus bars is dependent to its voltage. Therefore, for modeling, an index is regarded as follows:

$$
V I_{B V}=\sqrt{\sum_{i=1}^{N B}\left(V_{i, p u}-V_{r e f, p u}\right)^{2}}
$$

Where:

$V I_{B V}$ : Vulnerability index of bus bars due to the bus bars' voltage

$V_{i, p u}:$ ith bus voltage in per unit

$V_{\text {ref,pu }}:$ ith bus desired voltage in per unit

NB: Number of system bus bars.

Therefore, the vulnerability index of bus bars due to the bus bars' voltage vulnerability can be obtained according to Eq. (13):

$$
V I_{B}=W_{B V} \cdot V I_{B V}
$$

In which $\mathrm{W}_{\mathrm{BV}}$ is the weighting coefficient of $\mathrm{VI}{ }_{\mathrm{BV}}$ and can be determined based on the importance of each index.

\section{Generators Security Margin Index}

The vulnerability indices of generators can be measured based on the maximum production of generator active and reactive power separately. Of course, instead of the generator security margin, we can use optimal load flow to reduce production cost, but considering the importance of generators security, in this paper, as following equations, we use security or vulnerability indices.

$$
\begin{gathered}
V I_{g Q}=\sqrt{\sum_{i=1}^{N g}\left(\frac{Q_{g i}}{Q_{i . \max }}\right)^{2}} \\
V I_{g P}=\sqrt{\sum_{i=1}^{N g}\left(\frac{P_{g i}}{P_{i . \max }}\right)^{2}}
\end{gathered}
$$

Where:

$V I_{g Q}$ : Generators' vulnerability index for reactive power production or absorption

$V I_{g P}$ : Generators' vulnerability index for active power production

$Q_{g i}$ : Reactive power production or absorption by the ith generator

$Q_{i . \max }:$ Maximum reactive power production or absorption by the ith generator

$P_{g i}:$ Active power production or absorption by the ith generator

$P_{i \text { max }}$ : Maximum active power production or absorption by the ith generator

$\mathrm{Ng}$ : Number of generators.

Therefore, the vulnerability index of generators, totally, is obtained by the vulnerability indices VI ${ }_{\mathrm{gQ}}, \mathrm{VI} \mathrm{gP}$, according to Eq. (16):

$$
V I_{g e n}=W_{g Q} \cdot V I_{g Q}+W_{g P} \cdot V I_{g P}
$$

In which, $\mathrm{W}_{\mathrm{gP}}, \mathrm{W}_{\mathrm{gQ}}$ are weighting coefficients corresponding to the $\mathrm{VI}_{\mathrm{gP}}, \mathrm{VI}_{\mathrm{gQ}}$ indices, respectively. And these coefficients can be determined based on importance of each indicator.

Total vulnerability index of system, according to Eq (8) is consisting of the lines, bus bars and FACTS devices vulnerability indices.

\section{PLACEMENT ALGORITHM}

In this paper, placement is done in two ways: simultaneously and individually (firstly SVC, and then TCSC and finally UPFC). Placement algorithm can be expressed as Fig. 4. However, in non-simultaneous placement, firstly SVC and then TCSC and finally UPFC will be placed separately.

\section{NUMERICAL STUDIES}

For numerical studies, IEEE 30-buses test system is used. Given that, usually the installation of more than one FACTS device is not feasible for electrical power companies, so this paper assumes that the number of FACTS devices is determined by electrical power companies based on their type, and its placement is done by algorithm genetic only to maximize the network security margin indices. Therefore, it is assumed that the target will be the optimal placement of a UPFC, a TCSC and a SVC. Placement is done in two ways, once simultaneously and other time non-simultaneously (firstly SVC, then TCSC and finally UPFC). 
Series voltage source and the angle of UPFC are modeled by the amplitude in range of $(0-0.1)$ pu and $\pm \pi \mathrm{rad}$, respectively which this modeling is done according to Eqs. (4) to (7) as sources of active and reactive power injected adjacent to the bus transmission line in which UPFC is installed. Active and reactive powers injected at any stage of load flow iterations, according to the voltages obtained from the previous step are corrected. Compensating reactive power; UPFC and SVC are regarded as a source in operating range of $\pm 100 \mathrm{MVAr}$. Also, TCSC is modeled as the variable impedance with working range $(-0.7-+0.2) \mathrm{X}$ L. Simulation results for simultaneous and non-simultaneous placement are as the Tables (1) to (3).

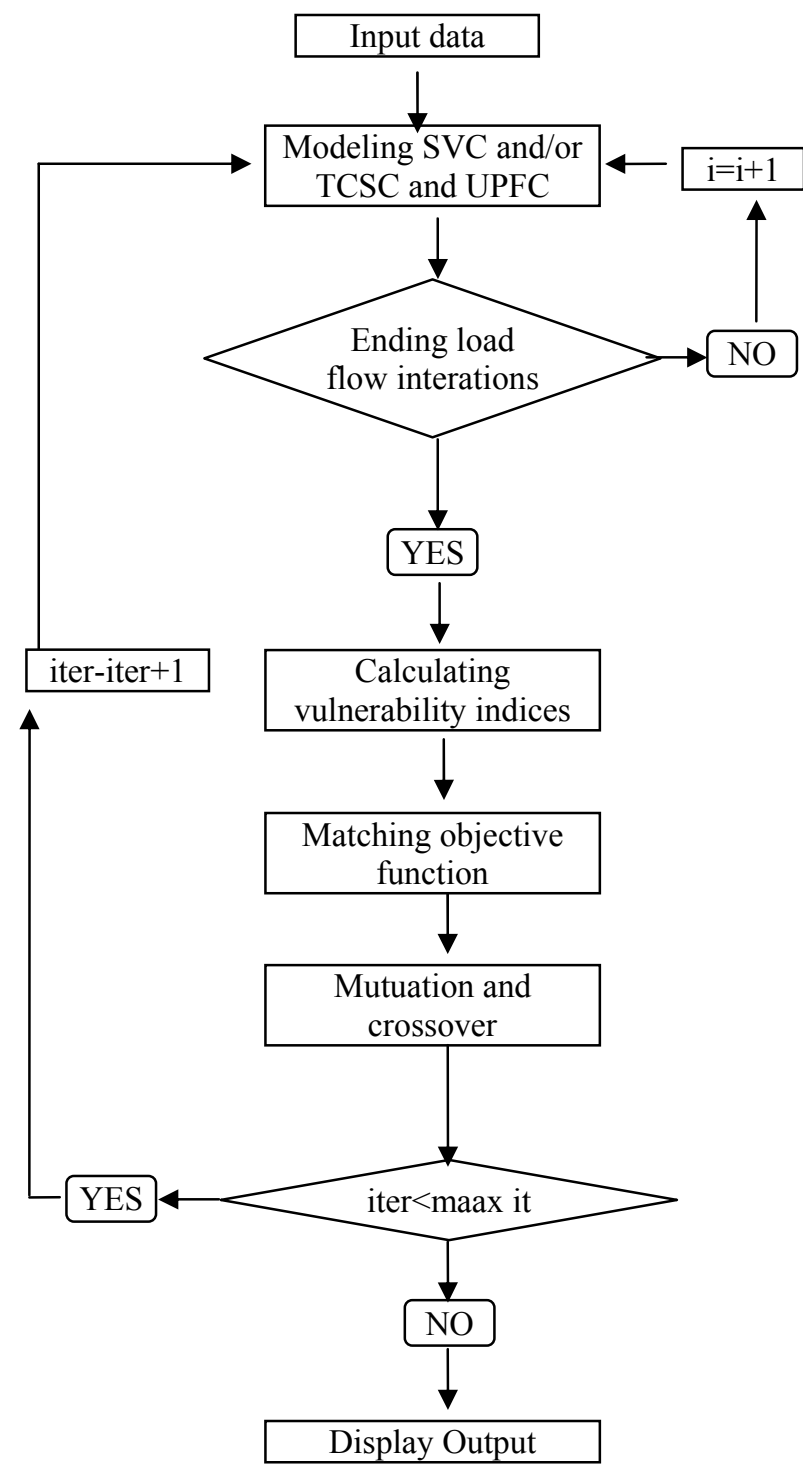

TABLE I. TABLE RESULTS OF FACTS DEVICES PLACEMENT

\begin{tabular}{|l|l|l|l|}
\hline Index & $\begin{array}{l}\text { simultaneous } \\
\text { placement }\end{array}$ & $\begin{array}{l}\text { Non-simultaneous } \\
\text { placement }\end{array}$ & $\begin{array}{l}\text { Without } \\
\text { FACTS }\end{array}$ \\
\hline
\end{tabular}

\begin{tabular}{|l|l|l|l|}
\hline & & & devices \\
\hline $\mathrm{VI}_{\text {sys }}$ & 2.0785 & 2.2255 & 3.4529 \\
\hline $\mathrm{VI}_{\text {gen }}$ & 0.9168 & 1.8104 & 2.3885 \\
\hline $\mathrm{VI}_{\text {bus }}$ & 0.2903 & 0.2180 & 0.199 \\
\hline $\mathrm{VI}_{\text {line }}$ & 0.8826 & 0.9378 & 0.8654 \\
\hline
\end{tabular}

TABLE II. FACTS DEVICES CHARACTERISTICS IN SIMULTANEOUS PLACEMENT

\begin{tabular}{|l|l|l|l|l|l|}
\hline $\begin{array}{l}\text { Type of } \\
\text { equipment }\end{array}$ & Location & $\begin{array}{l}\text { inserted Q } \\
(\text { MVAr) }\end{array}$ & $\mathrm{X}_{\text {se }}(\mathrm{pu})$ & $\begin{array}{l}\mathrm{V}_{\text {se }} \\
(\mathrm{pu})\end{array}$ & $\varphi_{\text {se }}(\mathrm{rad})$ \\
\hline TCSC & Line 7-6 & -- & 0.0943 & --- & --- \\
\hline UPFC & $\begin{array}{l}\text { Lines 22- } \\
21\end{array}$ & $\begin{array}{l}70=- \text { Qsh } \\
\text { Psh=0 }\end{array}$ & --- & 0.096 & 1.6965 \\
\hline SVC & Bus 5 & -70 & --- & --- & --- \\
\hline
\end{tabular}

TABLE III. FACTS DEVICES CHARACTERISTIC IN NONSIMULTANEOUS PLACEMENT

\begin{tabular}{|l|l|l|l|l|l|}
\hline $\begin{array}{l}\text { Type of } \\
\text { equipment }\end{array}$ & Location & $\begin{array}{l}\text { inserted Q } \\
(\text { MVAr) }\end{array}$ & $\mathrm{X}_{\text {se }}(\mathrm{pu})$ & $\begin{array}{l}\mathrm{V}_{\text {se }} \\
(\mathrm{pu})\end{array}$ & $\varphi_{\text {se }}(\mathrm{rad})$ \\
\hline TCSC & Line 7-6 & -- & 0.18 & --- & --- \\
\hline UPFC & Lines 8-6 & $\begin{array}{l}\text { Qsh=-34 } \\
\text { Psh=0 }\end{array}$ & --- & 0.1 & 1.4451 \\
\hline SVC & Bus 28 & -92 & --- & --- & --- \\
\hline
\end{tabular}

The results show that by non-simultaneous placement of a UPFC, a TCSC and SVC, vulnerability of a system decreases from 3.4529 to 2.2255 (without FACTS devices installations). Also, voltage profiles are improved according to the Fig. 5. With the simultaneous placement of the FACTS devices, system vulnerabilities decrease from 2.2255 to 2.0785 (in the non-simultaneous placement). Also, voltage profiles are improved in some bus bars.

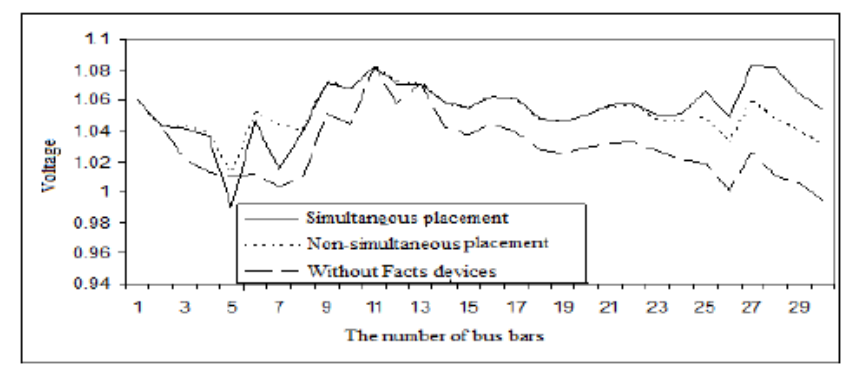

Figure 4. Voltage profiles of the bus bars

\section{CONCLUSION}

In this paper, an objective function consisting of generators, bus bars and lines vulnerability indices for optimal placement of facts devices including UPFC, SVC and TCSC 
has been presented. To calculate the vulnerability and network security indices, an appropriate model of mentioned devices to solve the load flow calculation is used. Also, in this paper, the optimal placement of facts devices has been done by two ways. In the first case, placement and installation of them is performed individually and in the next state the placement of these devices have been done simultaneously. For the case studies, IEEE 30-buses test system is selected and a UPFC, SVC and a TCSC are placed in the system simultaneously and non-simultaneously. Results show that these devices have better influences in the simultaneous placement mode than the non-simultaneous mode, and could improve voltage profile and network security margin.

\section{REFERENCES}

[1] I. Marouani, T. Guesmi, H. Haji Abdallah and A. Ouali, "Application of a Multiobjective Evolutionary Algorithm for Optimal Location and Parameters of FACTS Devices Considering the Real Power Loss in Transmission Lines and Voltage Deviation Buses", 20096 th International Multi-Conference on Systems, Signals and Devices.

[2] M. Saravanan, S. Mary Raja Slochanal, P. Venkatesh, J. Prince Stephen Abraham, "Application of Particle Swarm Optimization Technique for Optimal Location of FACTS Devices Considering Cost of Installation and System Loadability", Electric Power Systems Research 77 (2007) 276-283.

[3] Bongkoj Sookananta, "Determination ofFACTS Placement Using Differential Evolution Technique", 2009 International Conference on Electrical Engineering and Informatics 5-7 August 2009, Selangor, Malaysia.

[4] Feng Qian, Guangfu Tang, and Zhiyuan He, "Optimal Location and Capability of FACTS Devices in a Power System by Means of Sensitivity Analysis and EEAC", DRPT2008 6-9 April 2008 Nanjing China.

[5] J. Baskarana, V. Palanisamy, "Optimal location of FACTS Devices in a Power System Solved by a Hybrid Approach", Nonlinear Analysis 65 (2006) 2094-2102,

[6] QH Wu, Z. Evolutionary Computation, 2008. Lu and MS Li, TY Ji, "Optimal Placement of FACTS Devices by A Group Search
Optimizer with Multiple Producer", Evolutionary Computation, the 2,008th. CEC 2008. CEC 2008.

[7] Power Engineering, 2007 Large Engineering Systems Conference[Seventh] Phuong Hoang Kim, Tran Le Anh Tuan and Bach, "Optimal Placement of FACTS in Northern Power Transmission System Using an Opf Formulation of Vietnam", Power Engineering, 2007 Large Engineering Systems Conference .

[8] M. Majidi Q, S. Afsharnia, MS Ghazizadeh, A. Pazuki, "A New Method for Optimal Location of FACTS Devices in Deregulated Electricity Market", 2008 IEEE Electrical Power \& Energy Conference.

[9] Power Tech, 2007 IEEE Lausanne[9] Mahbube Zeraatzade, Ivana and Yong-Hua Song Kockar,, "Minimizing Congestion balancing Market Re-dispatch Costs by Optimal Placements of FACTS Devices", Power Tech, the 2,007th IEEE Lausanne .

[10] Z. Lu, MS Li, WJ Tang, and QH Wu, "Optimal Location of FACTS Devices by A Bacterial Swarming Algorithm for Reactive Power Planning",

[11] M. Gitizadeh, and M. Kalantar, "A New Approach for Congestion Management via Optimal Location of FACTS Devices in Deregulated Power Systems", DRPT2008 6-9 April 2008 Nanjing China.

[12] M. Majidi Q, S. Afsharnia, M. S. Ghazizadeh, A. Pazuki, "A New Method for Optimal Location of FACTS Devices in Deregulated Electricity Market", 2008 IEEE Electrical Power \& Energy Conference.

[13] Mónica Aloso and Hortensia Amaris, "Optimal Placement of FACTS Units for Minimizing the Impact of Voltage Sags in Power Networks With High Wind Energy Penetration", 20th International Conference on Electricity Distribution.

[14] T. Jain, SN Singhb and SC Srivastavab, "Dynamic ATC Enhancement Through Optimal Placement of FACTS Controllers", Electric Power Systems Research 79 (2009) 1473-1482.

[15] B. Kalyan Kumar, SN Singh and SC Srivastava, "Placement of FACTS Controllers Using Modal Controllability Indices to Damp Out PowerSystem Oscillations", IET Gener. Transm. Distrib., 2007, 1, (2), pp. 209-217.

[16] S. Sutha, and N. Kamaraj, "Optimal Location of Multi Type Facts Devices for Multiple Contingencies Using Particle Swarm Optimization", International Journal of Electrical and Electronics Engineering 1:12008 